\title{
Coronavirus Disease-19 Vaccines Best Reflect Effective Pharmaceuticals
}

\author{
Marco Cosentino $^{1}\left[\right.$ Marco $^{-1}$ Ferrari $^{1} \cdot$ Franca Marino $^{1}$
}

Received: 9 May 2021 / Accepted: 13 May 2021 / Published online: 18 May 2021

(c) The Author(s), under exclusive licence to Springer Science+Business Media, LLC, part of Springer Nature 2021

\section{Dear Editor,}

Most western countries, including USA, EU and UK, are building their mass Coronavirus disease-19 (COVID-19) vaccination campaigns on products derived from groundbreaking biotechnologies, for messenger RNA (Pfizer/BioNTech and Moderna) and DNA delivery through adenovirus vectors (Oxford/AstraZeneca and Johnson \& Johnson). The latter is shared by the Russian Federation as the Sputnik V vaccine (Jeyanathan et al. 2020). At the onset of the severe acute respiratory disease coronavirus-2 (SARS CoV-2) pandemic, only two viral vector-based vaccines against Ebola virus (however not using adenovirus vectors) were licensed for human use (Suschak and Schmaljohn 2019). In the face of a public health emergency imposed by COVID-19 pandemic the widespread public perception seen with professional scientific support that the vaccines being developed were reflective of what had already been available for tetanus, diphtheria, polio, measles, mumps, or rubella amongst others.

However, the current COVID-19 vaccines are distinct and in specific ways better reflect pharmaceutical drugs and should be considered as such. Conventional vaccines are preparations containing weakened or killed forms of the microorganism, some of its key antigenic determinants, or an inactivated form of toxin. Such preparations are expected to meet the host immune system at the site of injection, eventually resulting in stimulation of an immune response and in turn of an immunological memory. COVID19 vaccines are based squarely on messenger RNA or DNA delivery prepared by vector delivery. They contain active SARS-CoV-2 S protein RNA or DNA encased in excipients (lipids, salts and sucrose for RNA vaccines, an adenovirus

Marco Cosentino

marco.cosentino@uninsubria.it

1 Center for Research in Medical Pharmacology, University of Insubria, Insubria, Varese, Italy for DNA vaccines). Active ingredients are unable to directly affect the immune system, unless they undergo translation into the SARS-CoV-2 S protein by cells in which they penetrate through ribosomal processing. This occurs through ribosomal translation in the case of RNAs, and through preliminary nuclear episomal localization, and subsequent transcription and translation for DNAs. Rodent models clearly show that the expression kinetics of RNA delivered in lipid nanoparticles is dose-dependent, with known variability, and that the active ingredient undergoes systemic disposition, with bioavailability dependent on dose, route of administration, distribution, and the variable time courses of elimination (Pardi et al. 2015). On the other hand, the expression of DNA delivered by adenoviral vectors depends both on the amount and site of administration as well as on the proportion of quiescent as compared to proliferating cells where the gene is finally delivered (Athanasopoulos et al. 2017). Thus, such products exhibit classical pharmacodynamics and pharmacokinetics, which can affect their pharmacology.

It has been recently suggested that the SARS-CoV-2 S protein produced and released by the host cells previously targeted by vaccines may interact with its ACE2 receptor expressed on other cells, trigger inflammation, thrombosis, and other adverse reactions, eventually mimicking disease pathology (Angeli et al. 2021). Would this be the case, then such unintended consequences of vaccine-induced $\mathrm{S}$ protein production could depend on the cells, tissues and organs where production occurs; the amount of protein produced and released; and the time-course of its production and release. For example, expression of ACE2 receptors in human heart is a potential mechanism of heart injury during infection with infected with SARS-CoV-2 (Chen et al. 2020). However, interactions between vaccine-induced SARS-CoV-2 S protein and heart ACE2 receptors should be explored to determine if the recent reports suggesting that acute myocarditis could follow the administration of the COVID-19 vaccines is linked through cause and effect (Reuters 2021; García et al. 2021). In the same way, ACE2 
receptor genetic polymorphisms, which are presently assessed as biomarkers of susceptibility to SARS-CoV-2 infection and COVID-19 related complications (Devaux et al. 2020), should be also examined as potential markers of susceptibility to vaccine-induced adverse effects. Finally, but not least, assessing the relevance of SARS-CoV-2 S proteinACE2 receptor interactions for RNA and or DNA vaccineinduced adverse effects could also help identifying strategies aimed at increasing vaccine safety. This can occur by drugs able to interfere with ACE2 by S protein receptor binding (Bhowmik et al. 2021).

Thorough consideration and detailed characterization of pharmacodynamics and pharmacokinetics of RNA and DNA vaccines, including the pharmacogenetics of RNA and DNA translation and disposition, will likely provide a basis for dose individualization as well as for the identification of subjects at risk for adverse reactions, and in general for a rational management of such novel therapeutics.

\section{References}

Angeli F, Spanevello A, Reboldi G, Visca D, Verdecchia P (2021) SARS-CoV-2 Vaccines: Lights and Shadows. Eur J Intern Med Published online: April 29, 2021. https://doi.org/10.1016/j.ejim. 2021.04.019

Athanasopoulos T, Munye MM, Yáñez-Muñoz RJ (2017) Nonintegrating Gene Therapy Vectors. Hematol Oncol Clin North Am 31:753-770. https://doi.org/10.1016/j.hoc.2017.06.007

Bhowmik D, Nandi R, Prakash A, Kumar D (2021) Evaluation of flavonoids as 2019-nCoV cell entry inhibitor through molecular docking and pharmacological analysis. Heliyon 7:e06515. https:// doi.org/10.1016/j.heliyon.2021.e06515

Chen L, Li X, Chen M, Feng Y, Xiong C (2020) The ACE2 expression in human heart indicates new potential mechanism of heart injury among patients infected with SARS-CoV-2. Cardiovasc Res 116:1097-1100. https://doi.org/10.1093/cvr/cvaa078

Devaux CA, Rolain JM, Raoult D (2020) ACE2 receptor polymorphism: Susceptibility to SARS-CoV-2, hypertension, multi-organ failure, and COVID-19 disease outcome. J Microbiol Immunol Infect 53:425-435. https://doi.org/10.1016/j.jmii.2020.04.015

García JB, Ortega PP, Antonio Bonilla Fernández J, León AC, Burgos LR, Dorta EC (2021) [Acute myocarditis after administration of the BNT162b2 vaccine against COVID-19]. Rev Esp Cardiol Published online: Mar 20, 2021. doi: https://doi.org/10.1016/j.recesp. 2021.03.009

Jeyanathan M, Afkhami S, Smaill F, Miller MS, Lichty BD, Xing Z (2020) Immunological considerations for COVID-19 vaccine strategies. Nat Rev Immunol 20:615-632. https://doi.org/10.1038/ s41577-020-00434-6

Pardi N, Tuyishime S, Muramatsu H, Kariko K, Mui BL, Tam YK, Madden TD, Hope MJ, Weissman D (2015) Expression kinetics of nucleoside-modified mRNA delivered in lipid nanoparticles to mice by various routes. J Control Release 217:345-351. https:// doi.org/10.1016/j.jconrel.2015.08.007

Reuters (2021) Israel examining heart inflammation cases in people who received Pfizer COVID shot. https://www.reuters.com/ world/middle-east/israel-examining-heart-inflammation-casespeople-who-received-pfizer-covid-shot-2021-04-25/ (last visited: $1 / 5 / 2021)$.

Suschak JJ, Schmaljohn CS (2019) Vaccines against Ebola virus and Marburg virus: recent advances and promising candidates. Hum Vaccin Immunother 15:2359-2377. https://doi.org/10.1080/ 21645515.2019.1651140

Publisher's Note Springer Nature remains neutral with regard to jurisdictional claims in published maps and institutional affiliations. 